\title{
POR UMA REDISCUSSÃO DO CONCEITO DE INTERGENERICIDADE ${ }^{1}$
}

\author{
Vicente de Lima-Neto ${ }^{2}$ \\ Júlio César Araújo ${ }^{3}$
}

Resumo: Este ensaio tem como objetivo rediscutir a intergenericidade, conceito que estuda as misturas de gêneros. Com base nas reflexões de Bakhtin (2006 [1953]) sobre reelaborações e misturas de gêneros, buscamos argumentos que sustentem a tese de que o conceito de intergenericidade, tal qual vem sendo proposto pela Linguística de Texto, não contempla todas as diferentes formas de manifestação textual em que se misturam gêneros. Propomos três tipos de mesclas genéricas distintas: a mescla por intergenericidade prototípica, caracterizada pela fusão de traços de pelo menos dois gêneros; a mescla por gêneros casualmente ocorrentes; constituida por gêneros que não necessariamente se fundem, mas que coexistem numa relação simbiótica, voltada para um propósito comunicativo comum; e a mescla por gêneros intercalados, que envolve gêneros que podem pertencer a cenas enunciativas distintas.

Palavras-chave: Gêneros. Intergenericidade. Mesclas de gêneros.

\section{CONSIDERAÇÕES INICIAIS}

Esta indistinção dos gêneros é mais complexa que o tipo de confusão estilística que transformou Harry Houdini ou Richard Nixon em personagens de romances [...]. Questionamentos filosóficos parecem críticas literárias, debates científicos se assemelham a textos selecionados das belles lettres, fantasias barrocas são apresentadas como sérias observações empíricas [...]. O fenômeno generalizou-se tanto, e tornou-se tão evidente, que sugere que o que estamos observando não é apenas uma versão mais recente do mapa cultural [...]. e, sim, uma mudança no próprio sistema de mapear. (GEERTZ, 1983, p. 34)

\footnotetext{
${ }^{1}$ Trabalho desenvolvido no âmbito do projeto Práticas de Linguagens da Web: links entre gêneros, letramentos, hipermodalidade e convergências de mídias (Etapa II). Agradecemos à professora Elaine Cristina Forte-Ferreira, pela leitura crítica e atenta. Assumimos a responsabilidade por problemas remanescentes.

${ }^{2}$ Doutorando em Linguística pela UFC. Email: netosenna@gmail.com

${ }_{3}^{3}$ Professor do Programa de Pós-graduação em Linguística da UFC. Email: araujo@ufc.br.
} 
O que chama a atenção na epígrafe acima é o fato de o seu autor atentar para um fenômeno que intriga pensadores da linguagem desde a década de 20: as misturas genéricas. Geertz (1983), de um ponto de vista da etnografia interpretativista, observa que há mudanças ocorrendo nas práticas sociais das culturas. Parece haver uma reconfiguração do pensamento social em decorrência das hibridizações, logo, as formas de categorizar estão sendo alteradas em virtude do que acontece de novo, e os gêneros são bons exemplos das misturas que ocorrem numa dada sociedade.

Embora, em sua obra, o antropólogo não cite Bakhtin (2006), ambos partilham do mesmo ponto de vista sobre o gênero como uma entidade sociocultural. As práticas de linguagem nada mais são do que reflexos de práticas sociais, portanto, o gênero é tão complexo e heterogêneo quanto o é a sociedade onde está inserido.

Com base nessas considerações, o objetivo deste trabalho é discutir o conceito de intergenericidade, já posto pela literatura, e propor uma nova hipótese de trabalho que leve em conta o fato de as mesclas de gêneros serem mais complexas do que se tem colocado, mostrando que o conceito não dá conta dos diferentes tipos de misturas genéricas que existem.

\section{SOBRE MESCLAS GENÉRICAS}

Embora pareça ser recente, o estudo sobre mesclas genéricas já tem mais de oitenta anos. Bakhtin $(2005)^{4}$, estudando o romance polifônico de Dostoiévski, já apontava a maleabilidade em gêneros praticados na Grécia Antiga, quando evidenciou a mistura de padrões genéricos, tais como os de caráter estilístico e composicional, entre o diálogo socrático e a sátira menipeia, ambos gêneros do campo literário, que reelaboravam e subvertiam outros gêneros, como cartas, manuscritos, citações etc. Segundo o autor, a sátira menipeia talvez tenha sido um dos gêneros mais flexíveis da história da humanidade, com amplo emprego de gêneros intercalados, como novelas, cartas, discursos oratórios etc. Ela tinha tanto a capacidade de absorver gêneros menores quanto o de penetrar maiores, o que dificultava encontrar suas fronteiras estruturais.

${ }^{4}$ Estamos usando a edição de 2005, mas a edição original russa data de 1929. 
Logo se vê que as misturas de gêneros não são práticas de linguagem atuais. $\mathrm{O}$ gênero citado por Bakhtin, a sátira menipeia, já era utilizado no século III a.C.. O estudo de Fix (2006)5 é mais aprofundado, e a autora foi a primeira a se debruçar especificamente sobre o fenômeno ${ }^{6}$. A linguista alemã argumenta que o cânone e a dissolução do cânone, típicos do comportamento das sociedades, está se refletindo nos textos cada vez com mais frequência. Logo, textos publicitários (sejam políticos, sejam comerciais), jornalísticos, aforismos, pichações etc., por terem a característica de chamar a atenção do público, "são formados com recursos da dissolução do cânone: variações, montagens de texto, transgressões e misturas textuais e estilísticas" (FIX, 2006, p. 264). Para esta variação, a autora designa a nomenclatura "intertextualidade tipológica ${ }^{7 ’}$. Então,

uma montagem de padrões de textos poderia ser descrita como um acoplamento de vários exemplares de textos que pertencem, cada um, a outro tipo de padrão, mas que seguem uma única intenção textual. [...] Uma transgressão de padrões de textos ocorre quando um exemplar de texto tem as características de um padrão de texto e, além disso, traços que não podem ser associados, inequivocamente, com nenhum padrão de texto. (FIX, 2006, p. 264).

Logo, para a autora, qualquer tipo de mescla, transgressão de regras ou apagamento de fronteiras leva à "dissolução do cânone”. Essa quebra de paradigmas representa um recurso estilístico dos textos, elaborados criativamente de forma a chamar a atenção dos leitores. Todas essas fugas do tradicional são fabricadas para levar a um objetivo específico.

\footnotetext{
${ }^{5}$ Tivemos acesso ao texto de Fix traduzido por Wieser, em 2006. A publicação original data de 1996.

${ }^{6}$ Há trabalhos anteriores que falam de misturas de gêneros, como o próprio Bakhtin (1929), Geertz (1983), Bhatia (1993), mas nenhum se detém unicamente sobre este fenômeno linguístico.

${ }^{7}$ Por uma questão terminológica, vale a pena salientar que intertextualidade tipológica, para Fix, é a intertextualidade inter-gêneros de Marcuschi (2002) ou intergenericidade de Koch (2004). A intertextualidade tipológica para estes últimos autores diz respeito a um gênero que contém, em sua estrutura, a presença de vários tipos textuais, os quais são entendidos como unidades estruturais, organizacionais e autônomas que nos ajudam a realizar o ato comunicativo. São essas estruturas que fazem com que reconheçamos se um texto é do tipo narrativo ou descritivo, por exemplo.
}

NETO; ARAÚJO - Por uma rediscussão do conceito de intergenericidade 
Além de Fix (2006), outros autores (MARCUSCHI, 2002; 2008; $\mathrm{KOCH}$, 2004; KOCH; ELIAS, 2006; KOCH; BENTES; CAVALCANTE, 2007) atribuem à intertextualidade os estudos das misturas de gêneros. Para Marcuschi (2002), quando um gênero tem uma determinada função, mas se utiliza da forma de outro, constrói-se o fenômeno da intertextualidade inter-gêneros. Para entender melhor, o autor, baseado em Fix (2006), sugere o seguinte gráfico:

Gráfico 1 - Gráfico da intertextualidade inter-gêneros:

\section{INTERGENERICDADE}

Função do

Gênero A

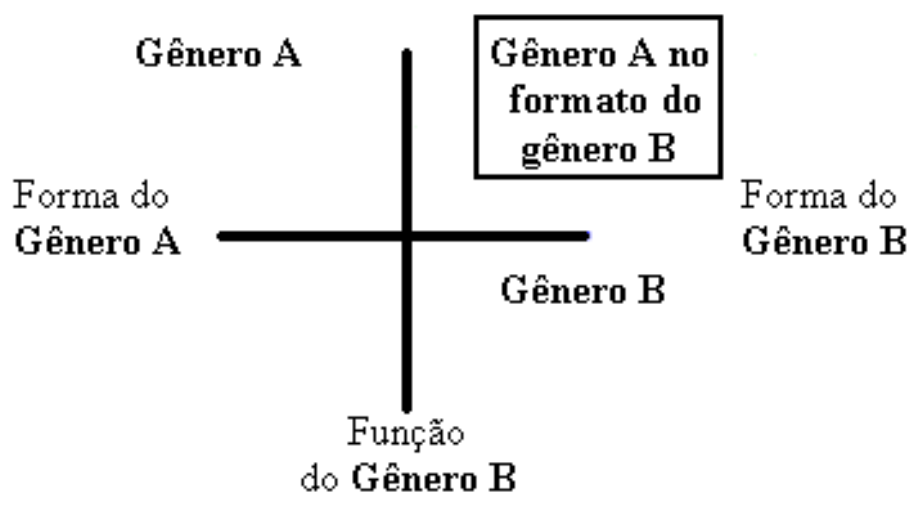

Fonte: Marcuschi (2008, p. 18) (adaptado).

O gráfico mostra como se dá esse tipo de relação genérica: de um lado, há o gênero A, com características formais e funcionais, e, do outro, o gênero B. A função, neste caso, diz respeito ao propósito comunicativo. A interseção entre os eixos gera um enunciado híbrido cuja forma será a de um gênero, e a função (propósito), de outro. Para 
Marcuschi (2008, p. 166), “isso não deve trazer dificuldade alguma para a interpretabilidade, já que impera o predomínio da função sobre a forma na determinação interpretativa do gênero [...]”, ou seja, há a prioridade no propósito para a definição do gênero, minimizando outros elementos que contribuem para resgatar a sua identidade.

Além desse posicionamento, numa obra sobre intertextualidade, Koch, Bentes e Cavalcante (2007) fazem uma distinção entre intertextualidade lato sensu e stricto sensu. A primeira é constitutiva de todo e qualquer discurso, ou seja, neste caso, qualquer enunciado é intertextual, pois é resposta a enunciados anteriores e potencializa ulteriores. Esta definição é tributária dos baldrames bakhtinianos de linguagem, pois ela tem suas bases no conceito de dialogismo de Bakhtin, para quem não existe um enunciado que não seja uma resposta a outro já proferido ou uma antecipação a outro que se vai proferir. A segunda

ocorre quando, em um texto, está inserido outro texto (intertexto) anteriormente produzido, que faz parte da memória social de uma coletividade ou da memória discursiva dos interlocutores. Isto é, em se tratando de uma intertextualidade stricto sensu, é necessário que o texto remeta a outros textos ou fragmentos de textos efetivamente produzidos, com os quais estabelece algum tipo de relação. (KOCH; BENTES; CAVALCANTE, 2007, p. 17).

Neste caso, só haverá intertextualidade quando houver a presença de um intertexto - entendido, então, como um fragmento de texto já efetivamente produzido, o qual permite estabelecer uma relação com o de origem.

Quando um gênero mantém relações com outro, seja quanto à construção composicional, ao conteúdo temático ou ao estilo, temos, segundo as mesmas autoras, outra forma de intertextualidade: a intergenérica. Dentro da tipologia estabelecida, a intergenericidade (ou intertextualidade intergenérica, como entendem as autoras) parece não se enquadrar nem na intertextualidade lato sensu, pois, nesse caso, na 
grande maioria das vezes, a relação dar-se-ia entre dois gêneros, não entre dois textos; nem na stricto sensu, pois o que permitiria correlacionar um gênero ao outro seriam traços de genericidade, como estrutura composicional, conteúdo, estilo ou propósito comunicativo.

Ainda em se tratando da intergenericidade, Pagano (2001) não atrela o fenômeno à intertextualidade. Para ela, os gêneros são

categorias históricas, aparentemente estáveis, porém sujeitas a um processo de transformação contínua. Nesse processo, gêneros existentes mudam a partir de modificações na situação social na qual exercem uma função ou novos gêneros podem surgir a partir de transformações ostensivas daqueles já existentes. (PAGANO, 2001, p. 87).

Então, como essa transformação, à qual estão sujeitos os gêneros, já é constitutiva de sua estrutura, para a autora, a hibridização é inerente às formações genéricas. Além disso, a hibridização não ocorre somente com gêneros antigos, mas também com os novos, como, por exemplo, o e-mail, que é híbrido da carta, telefonema, telegrama etc. Elucidemos o fenômeno, observando a figura 1, a seguir.

Em princípio, um leitor pouco atento diria tratar-se do gênero currículo, a partir do momento em que se baseia na estrutura para identificação do enunciado. Este é o ponto de vista defendido por Askehave e Swales (2001), quando afirmam que a primeira coisa com que o leitor se depara é a forma. Entretanto, quando se lê o que está escrito, vê-se que, na verdade, não se trata de um currículo, mas, sim, de uma piada, inclusive, eivada de preconceitos linguísticos. O sentido do texto é construído quando as informações sobre a formação acadêmica de Lula - então presidente do Brasil - são lidas. Essas informações trazem problemas de ortografia não aceitáveis para o gênero, além de informações desnecessárias, que teriam como fim provocar o riso. $\mathrm{O}$ gênero piada será reconhecido quando o leitor mover esquemas cognitivos que recuperem informações das mais variadas naturezas, principalmente no que diz respeito ao conhecimento que ele tenha sobre o personagem em questão, sobre o local onde este texto foi postado - o 
site Desciclopédia ${ }^{8}$ - e, principalmente, sobre os gêneros que estão envolvidos no processo: o currículo, do qual se utiliza a forma; e a piada, da qual se extrai o propósito comunicativo geral - provocar o riso.

Figura 1 - Intertextualidade intergenérica:

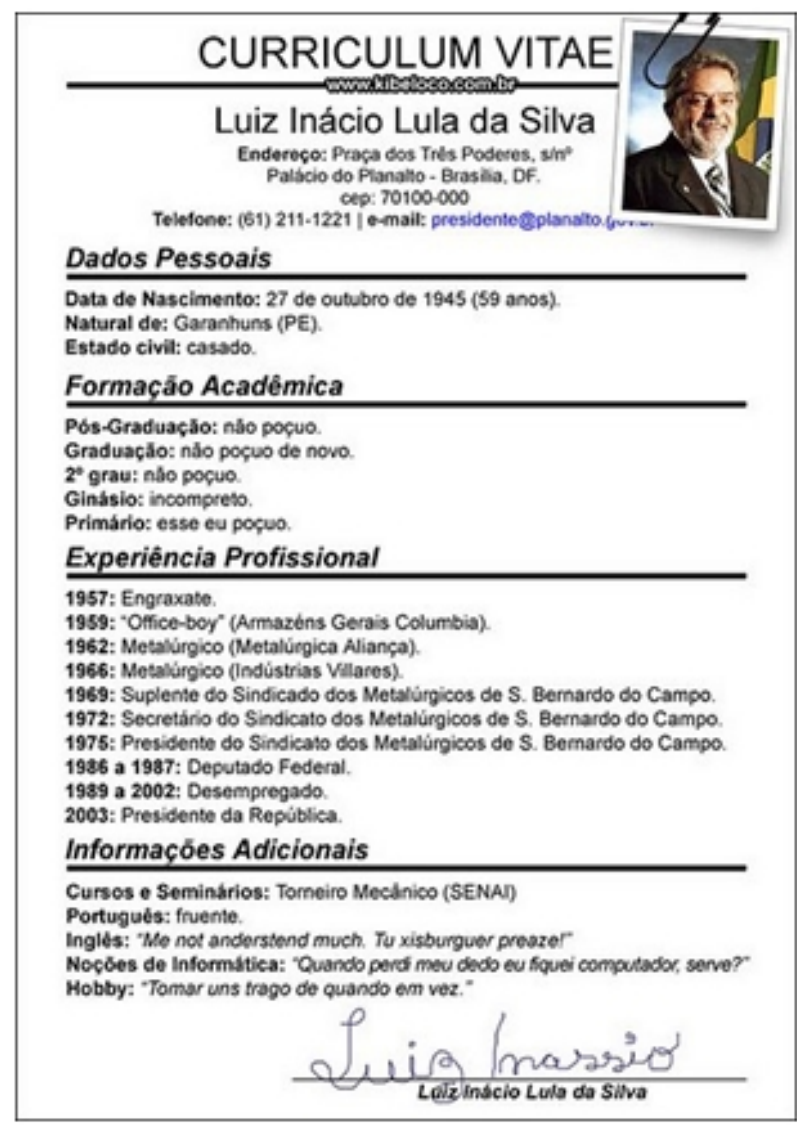

Fonte: <http://desciclo.pedia.ws/wiki/Luiz_Inácio_Lula_da_Silva>.

${ }^{8} \mathrm{O}$ site da Desciclopédia - www.desciclo.pedia.ws - é uma paródia da Wikipedia, esta última considerada a maior enciclopédia virtual do mundo. No caso da Desciclopédia, trata-se de uma "enciclopédia humorística", já que seu conteúdo é constituído por artigos escritos colaborativamente de maneira sarcástica.

NETO; ARAÚJO - Por uma rediscussão do conceito de intergenericidade 
Relevante para essa interpretação é também a assinatura, que traz o nome grafado sem obediência à norma ortográfica da língua portuguesa e com traços de quem adquiriu a escrita tardiamente, provavelmente já adulto, o que poderia levar a imaginar que, pelo fato de Lula não ter ensino superior ${ }^{9}$ - característica que parece ser necessária para o cargo que ocupa - ele seria quase analfabeto e não teria os atributos exigidos para ocupar a presidência.

Ao reconhecer esta construção híbrida como uma piada, o leitor terá se utilizado, nos dizeres de Koch (2004), de sua competência metagenérica, a qual possibilita que possamos interagir de forma conveniente com determinados gêneros, por mais desconhecidos que sejam, e permite a produção e a compreensão dos gêneros discursivos.

Em suma, embora seja constitutivo dos gêneros o seu potencial de hibridização, tem-se defendido, pelo menos nos estudos da Linguística de Texto, que as mesclas acontecem quando se misturam dois elementos genéricos distintos: a estrutura de um gênero $\mathrm{A}$ e o propósito (função) de um gênero $B$, o que culminará na identificação do gênero $B$, já que o propósito é o seu principal elemento definidor. Para didatizar essa explicação, teríamos, numa fórmula matemática, algo como

\section{Forma do Gênero A + Propósito de Gênero B = Gênero B}

Aplicando a equação acima à figura analisada, teríamos, então, ESTRUTURA DO CURRÍCULO + PROPÓSITO DA PIADA = PIADA (ou um gênero de natureza humorística). Queremos mostrar que considerar apenas essas características para as misturas acontecerem seria limitar a realidade desse tipo de mescla. Como veremos, há diferentes tipos de misturas de gêneros, e a terminologia "intertextualidade intergenérica” merece ser repensada. Vejamos o porquê.

\footnotetext{
${ }^{9}$ Nota-se que, para que o objetivo seja alcançado, é necessário ter esse conhecimento prévio sobre as origens do ex-presidente. Tal conhecimento de mundo, no gênero piada, parece ser ainda mais exigido para a construção do sentido, pelo fato de ele deixar, propositalmente, lacunas a serem preenchidas pelo leitor.
} 


\section{REPENSANDO UM CONCEITO...}

Por que atribuir à intertextualidade a responsabilidade pela designação do fenômeno em questão se nem sempre há relação entre textos, mas entre (elementos distintos de) gêneros? Para que haja uma intertextualidade (pelo menos stricto sensu), necessária é a presença de um intertexto, considerado uma "co-incidência de fragmentos de textos" (KOCH; BENTES; CAVALCANTE, 2007, p. 121). Então, analisando a figura 1 novamente, reconhece-se um elemento de um gênero A e outro elemento de um gênero $B$, não necessariamente uma materialidade verbal que permita recuperar outro texto. Cavalcante (2007, p.1) lança uma proposta:

Assim, não importa qual o tipo de remissão - se ao léxico, se a estruturas fonológicas, a estruturas sintáticas, ao gênero, ao estilo, ao tom -, haverá intertextualidade sempre que, intencionalmente, o enunciador estabelecer um diálogo entre o texto que está produzindo e outro(s), supondo que o co-enunciador conseguirá reconhecer a interseção entre eles, ou seja, que será capaz de identificar o intertexto.

Mesmo assim, não fica claro qual é o intertexto numa relação intergenérica. Embora saibamos que os textos pertencem a gêneros (logo, estes, entidades abstratas, se materializam naqueles, concretas), o leitor, participante de uma determinada comunidade discursiva (SWALES, 1990; 1992) e usuário de determinados gêneros, consegue recuperar alguns elementos de um determinado gênero (como estrutura composicional, propósito comunicativo etc.), não necessariamente uma materialidade verbal. $\mathrm{Na}$ verdade, tais questionamentos convergem para o conceito de texto, algo muito discutido em Linguística Textual e longe de ser unânime ${ }^{10}$. Não convém aqui discutir toda a historicidade do conceito, mas, para que se mantenha operante a expressão intertextualidade intergenérica, é necessário o alargamento do conceito

${ }^{10}$ Para uma discussão sobre o conceito de texto, remetemos o leitor a Hanks (2008).

NETO; ARAÚJO - Por uma rediscussão do conceito de intergenericidade 
de texto, de intertextualidade e, por conseguinte, o de intertexto, que pode ser entendido como qualquer elemento que possibilite fazer referência a outro texto ou a outro gênero, e não somente à materialidade verbal. Numa relação intergenérica, o intertexto pode ser a estrutura composicional, o conteúdo temático ou até mesmo o estilo ou o suporte, como veremos em seguida.

Embora os conceitos de gênero e texto estejam muito relacionados, um gênero não é reconhecido somente pela presença de um texto, mas também por um conjunto de elementos (estrutura composicional, estilo, propósito e/ou suporte, por exemplo), o que significa dizer que a intergenericidade não é garantia teórica para a intertextualidade - e será, desde que haja um alargamento do conceito de texto, de intertexto e de intertextualidade, conforme já argumentamos. Em função disso, neste trabalho, preferiremos o termo mescla por intergenericidade prototípica no lugar de intertextualidade intergenérica por dois motivos: primeiro porque a intergenericidade é apenas um dos tipos de possibilidades de mesclar gêneros; segundo porque tal expressão sinaliza para misturas de gêneros que não sejam reconhecidas única e exclusivamente por seu elemento textual ou verbal. Para explicar este último argumento, vejamos na figura 2 a seguir um exemplo do próprio Marcuschi (2002, p. 31), usado para demonstrar a intertextualidade intergêneros.

Esse texto foi publicado em um jornal, mais precisamente na seção de Opinião. Segundo a análise feita por Marcuschi (2002), além de fazer uma intertextualidade com o poema "E agora, José?", de Carlos Drummond de Andrade, o colunista se utiliza da estrutura do poema com o propósito de argumentar. Nesse caso, o produtor quer chamar a atenção para as "falcatruas" que corriam à época, no Governo Federal. Marcuschi (2002) sustenta que existe a forma de um gênero - o poema a serviço da função de outro - do artigo. Partindo dessa observação, o linguista admite que o propósito comunicativo acaba sendo o definidor dessa configuração híbrida. 
Figura 2 - Artigo de opinião na forma de poema:

\begin{tabular}{|c|c|}
\hline $\begin{array}{l}\text { Um novo José } \\
\text { Josias de Sousa }\end{array}$ & $\begin{array}{l}\text { Diga: ora Drummond, } \\
\text { Agora FMI }\end{array}$ \\
\hline 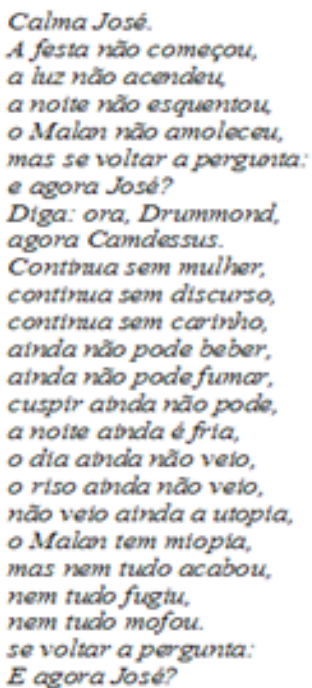 & 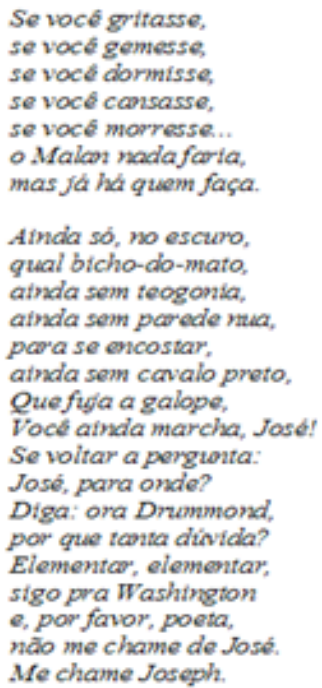 \\
\hline
\end{tabular}

Fonte: Marcuschi (2002, p. 30).

Embora Marcuschi tenha mostrado evidências empíricas que apontam que a hibridização se dá no nível forma/função, ele deixa de considerar o suporte que veicula o texto, o qual, no nosso entender, é o traço caracterizador do gênero. O leitor só consegue resgatar o propósito do gênero artigo de opinião e consegue vislumbrar a ação social que realiza porque, sociocognitivamente, ele reconhece um espaço no jornal destinado a este gênero (geralmente uma seção de um caderno do jornal) que está sendo preenchido aparentemente por um poema. Se este texto fosse veiculado de outra forma, avulso ou em outra mídia, muito

NETO; ARAÚJO - Por uma rediscussão do conceito de intergenericidade 
dificilmente seria identificado como um artigo de opinião ${ }^{11}$. Então, o que foi analisado como forma de um gênero A misturado ao propósito de um gênero B poderia ser repensado, pois o propósito só vem depois de ser identificado o suporte. A mistura deveria se caracterizar, então, como forma de um gênero $A+$ suporte de um gênero $B+$ traços estilísticos do gênero B (argumentação/ posicionamento), para então enxergar-se um artigo.

Isso acaba se refletindo no gráfico da intertextualidade intergêneros (gráfico 1), construído num plano cartesiano bidimensional, o qual tem em sua composição espaço apenas para duas características do gênero: forma e função. Nesse caso, o exemplo utilizado pelo autor não se enquadraria no gráfico, pois outra variável do gênero tem de ser levada em conta: o suporte. Como dissemos, um gênero não se restringe apenas a texto, à forma e à função. Portanto, a fórmula que sugerimos para que se compreenda o fenômeno em questão é a seguinte:

\section{Traço X do Gênero A + (Traço Y do Gênero $B+\ldots)$ + Propóstito do Gênero $\mathrm{C}=$ Gênero $\mathrm{C}^{*}$}

O Traço X do gênero A pode ser algo variável, mas que evoque alguma característica de algum gênero: estilo, composição, forma, suporte etc. Os parênteses sugerem possibilidades de inclusão de outros traços/gêneros na composição de um gênero híbrido ${ }^{12}$. O elemento Propósito do gênero $\mathrm{C}$ quase sempre aparecerá, em virtude de ele ser o traço privilegiado na definição de um gênero, conforme defendem Askehave e Swales (2001); por conseguinte, o resultado dessa mistura tende a ser o gênero C. Entretanto, simbolizamos com asterisco a possibilidade de não ser o propósito comunicativo o traço definidor. Marcuschi (2002) traz o exemplo que nos mostra isso, já que, no caso do artigo de opinião em forma de poema, o suporte impera.

11 Até mesmo se fosse publicado na mesma mídia, mas em outra seção do jornal, provavelmente haveria certo estranhamento por parte dos leitores, em virtude de não haver elementos linguísticos que indiquem se tratar de um artigo. 12 Em Lima-Neto (2009), foram encontrados exemplares híbridos que trazem resquícios de três gêneros. 
Ao que parece, o fenômeno da intergenericidade diz respeito somente a algumas questões próprias de um determinado gênero, a saber, a construção composicional, o estilo, o conteúdo temático, o propósito comunicativo e o suporte. Entendemos que haverá intergenericidade quando for possível enxergar, num mesmo enunciado, traços de pelo menos dois gêneros, e um deles prevalecer para a sua identificação. Geralmente esse traço é o propósito comunicativo. Suspeitamos que, por ser um enunciado híbrido e fabricado, o produtor tem a intenção de inovar, chamando a atenção do leitor de forma que este consiga recuperar traços dos dois gêneros. Mas, por sua competência metagenérica, ele reconhecerá o traço que se destacará para identificar o gênero, daí o fato de, antes de tudo, o gênero ser um constructo sociocognitivo. Mesmo assim, a mescla por intergenericidade prototípica é apenas um dos tipos de mesclas possíveis.

\subsection{DA MESCLA POR GÊNEROS CASUALMENTE OCORRENTES}

$\mathrm{Na}$ mescla por intergenericidade prototípica, como vimos, os traços de gêneros distintos se fundem, num mesmo espaço enunciativo, e um deles se destaca para identificação do gênero. Uma mistura de outra natureza também ocorre de forma mais comum do que se imagina (ver figura 3 a seguir).

Paiva (2009) reivindica o estatuto genérico do infográfico, que pode ter duas naturezas: a de caráter jornalístico, "que é utilizado para complementar a informação veiculada em uma notícia ou reportagem e geralmente explica um fato trazido nesses textos com o propósito de explicar como ele funciona, como aconteceu ou age" (PAIVA, 2009, p. 4); e a de caráter didático, "pois possui caráter didático, ao apresentar-se sem o acompanhamento de uma reportagem ou notícia". 
Figura 3: Mescla por gêneros casualmente ocorrentes:

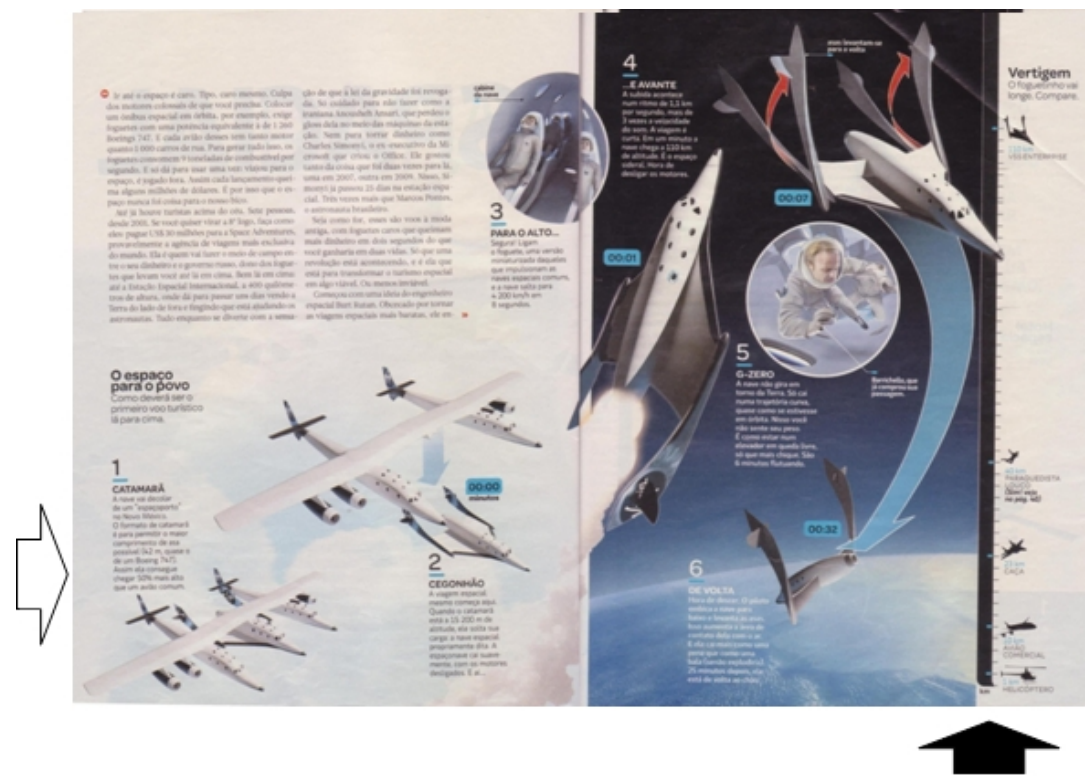

Fonte: Superinteressante, n. 279 (p. 72-73).

Analisando a figura 3, deparamo-nos com um infográfico que faz parte da reportagem Turismo Espacial ${ }^{13}$, da revista Superinteressante. Esta revista traz curiosidades culturais e científicas e é voltada para um público mais jovem. $\mathrm{Na}$ matéria em destaque, o tema são voos comerciais para o espaço, que estão ficando mais fáceis de acontecer em função do uso de uma espaçonave mais econômica que os foguetes.

Vê-se, pelas setas em destaque, que há um infográfico inserido na reportagem, e ele, naturalmente, auxilia nas informações trazidas pela reportagem, esta apenas em materialidade verbal. Se considerarmos a reportagem um gênero já estabilizado no campo jornalístico, e o infográfico um outro gênero, conforme atesta Paiva (2009), estamos diante de uma configuração híbrida, a qual chamamos de mescla por gêneros casualmente ocorrentes.

13 A matéria tem seis páginas, das quais só recortamos duas, que atende aos propósitos deste trabalho. O título da matéria, na revista, se encontra nas duas páginas anteriores. 
Não faz parte da estrutura do gênero reportagem compor-se de um infográfico sempre, embora isso possa acontecer, naturalmente. Ao que tudo indica, o infográfico está a serviço da reportagem, pois ela parece ter uma hierarquia sobre os demais gêneros que poderiam compor essa mescla. Se ela for retirada, o infográfico, pelo menos o que está em tela, pouco dirá, até porque esta é a sua natureza: complementar e ilustrar as informações trazidas na reportagem ${ }^{14}$. Em contrapartida, a reportagem sobrevive à ausência do infográfico, embora claramente com menos informações didáticas.

Independentemente disto, outra característica que serve para diferenciar os dois tipos de mistura é que esta se configura por unir dois gêneros (ou mais) que podem ter bem delimitadas as suas fronteiras estruturais, de forma que um não ocupe o espaço do outro. Kress e van Leuween (2006) trazem a categoria de framing, estudada na macrofunção composicional, para atestar esse fato: a disposição de informações nesta configuração híbrida aparece demarcada por elementos multimodais, como a presença de imagens que são explicadas por pequenos textos iniciados por uma numeração que vai de 1 a 6 - dispostos pela página de forma que fique clara a relação entre materialidade verbal/imagética. Além disso, na segunda página da figura 3, a cor de fundo também é alterada para preto, o que também demonstra tal enquadramento.

Além disso, é possível atestar que um gênero se utiliza do outro para atingir um determinado propósito - no caso, ambos têm o intuito de deixar informar o leitor. Diferentemente do que ocorre na mescla por intergenericidade prototípica, que funde características de dois gêneros, neste exemplo, a reportagem se utiliza do infográfico, sendo que cada gênero tem o seu espaço reservado, pois a natureza multimodal do infográfico facilita a compreensão do leitor. Alheio a estas duas mesclas, uma outra merece ser discutida.

\footnotetext{
${ }^{14}$ Saliente-se o fato de existirem infográficos mais autônomos, muito utilizados na própria Revista Superinteressante. Daí um dos bons argumentos para Paiva (2009) reivindicar o estatuto genérico do infográfico.
}

NETO; ARAÚJO - Por uma rediscussão do conceito de intergenericidade 


\subsection{MESCLA POR GÊNEROS INTERCALADOS}

O último tipo de mescla que trazemos para discussão neste trabalho parte do conceito de reelaboração, de Bakhtin (2006). Para este autor, os gêneros (geralmente) secundários absorvem primários, os quais perdem algumas de suas características originais e passam a existir em função do secundário, mais complexo. No caso, o exemplo de Bakhtin foi o romance (secundário), objeto de sua análise, que tinha como característica bastante comum absorver outros gêneros, como a carta e a conversa cotidiana. Então, a simples presença de um gênero em outro já constitui uma mescla, pois, do ponto de vista da recepção, o leitor identificará outro gênero, mas saberá que ele não cumpre, ali, seus objetivos próprios, mas, sim, os do gênero onde está inserido. Mas resumir a interpretação desse tipo de relação entre gêneros a apenas esse aspecto é não contemplar a natureza do fenômeno formativo de determinados gêneros. Por essa razão, julgamos relevante uma análise mais acurada por meio da qual possamos chegar ao entendimento da natureza dessa mistura genérica.

Retornando ao exemplo dado por Bakhtin em sua Estética da criação verbal, quando uma carta compõe um romance, ela perde suas características naturais e ganha traços do gênero e do campo que a absorveram. Se investigarmos isso sob o ponto de vista do leitor do romance, a hipótese de que ele conseguirá identificar o gênero transmutante (aquele que absorve outro gênero) e distingui-lo do transmutado (o gênero absorvido) seria, no mínimo, passível de sustentação ${ }^{15}$. A análise, possivelmente, revelaria que, embora o leitor soubesse que, no romance, a carta perde suas características próprias e só passa a existir em função da realidade desse gênero secundário, a carta consegue, ao mesmo tempo, conservar seus traços naturais e ser um componente do romance. Entretanto, conforme mostrou Zavam (2009), se o mesmo objeto de estudo for investigado sob a enunciação das

\footnotetext{
15 Transmutante e transmutado são categorias relacionadas ao fenômeno da transmutação de gêneros sugeridas por Araújo (2006), ao analisar a constelação dos gêneros chats.
} 
personagens da obra ${ }^{16}$, aquela carta é um gênero genuíno e pode, por exemplo, ter sido enviada ou produzida por algum personagem do romance.

Em síntese, a carta tem, ontologicamente, o status de gênero e está imersa num outro, o romance, mas este não traz, em todos os seus exemplares, cartas como se fizessem parte de sua estrutura. Esta absorção faz parte da natureza do gênero romance, profundamente maleável e passível de receber outros gêneros, mas não podemos afirmar, por exemplo, que todos os romances têm cartas em sua composição. Isso em muito se assemelha à mescla por gêneros casualmente ocorrentes, mas, se nos lembrarmos de determinados romances que foram escritos somente com base em cartas, como Os sofrimentos do jovem Werther ${ }^{17}$, veremos que, sem elas, o romance não existiria. O que queremos dizer é que, diferentemente da mescla por gêneros casualmente ocorrentes, que não obriga necessariamente a vinculação entre dois gêneros, este tipo de mescla exige. Além disso, é possível enxergar, nessa constituição híbrida, gêneros que estão sob cenas enunciativas diferentes. Drácula (STOKER, 2007) também é um bom exemplo desse tipo de romance.

Esta obra, por exemplo, é um romance constituído por diários, cartas e relatos, como se pode ver destacado na figura 4, que traz o seu índice. Aqui detectamos três gêneros (diário, relato e carta) como constituintes de um gênero maior (o romance), com a diferença de que este não traz aqueles três gêneros como parte de sua organização retórica, mas tão somente um grande potencial de absorvê-los sem danos para a sua estrutura e para a recepção do leitor. Naturalmente esses três gêneros são reelaborados, perdem suas características peculiares dos campos de onde procederam e passam a constituir o romance, neste caso, eminentemente híbrido. Entretanto, se ajustarmos a lupa com o foco para a enunciação das personagens, carta, diário e relatos serão considerados ainda gêneros do campo do cotidiano, "só que o cotidiano dos personagens" (ZAVAM, 2009, p. 53). Não estamos assumindo aqui

\footnotetext{
${ }^{16}$ Aprofundar uma análise dessa natureza, entretanto, seria entrar no campo literário e se distanciar do campo linguístico.

${ }^{17}$ A obra de Goethe é o romance que marca o início do Romantismo alemão e é construído com base em cartas enviadas por Werther, o herói, a Guilherme, o leitor.
}

NETO; ARAÚJO - Por uma rediscussão do conceito de intergenericidade 
uma perspectiva de análise literária, mas tão somente o fato de que o gênero romance, por sua constituição complexa e extremamente maleável, pode comportar outros gêneros - que circulam socialmente e são reconhecidos por uma determinada comunidade - em sua organização retórica.

Figura 4 - Índice do romance Drácula:

\section{Indice}

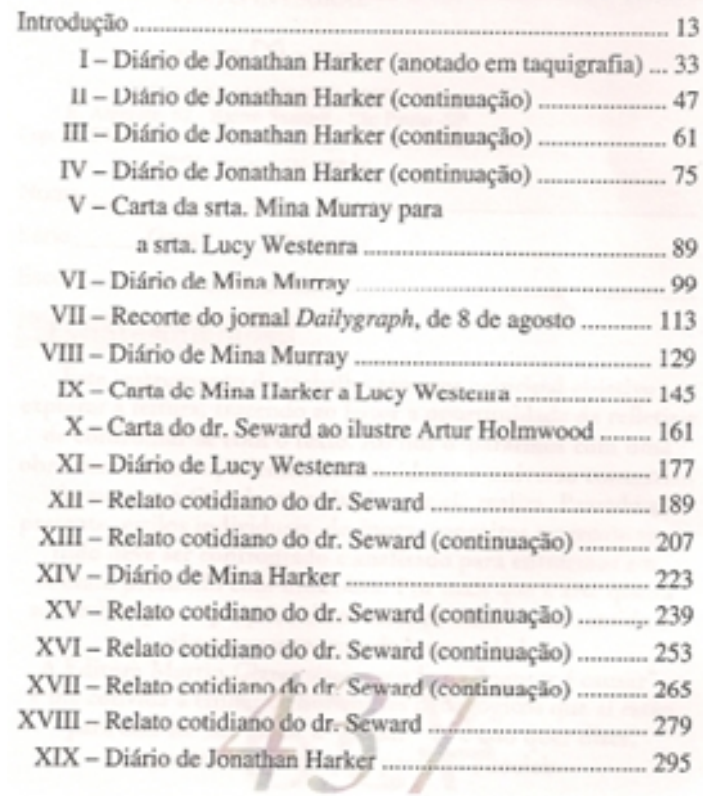

Fonte: Stoker (2007). 
A natureza do romance Drácula, por exemplo, implica dois fatores que devem ser levados em consideração pela Análise de Gêneros: o primeiro é o fato de que um leitor que tenha um bom conhecimento de mundo reconhecerá outros gêneros que ali se materializam - como uma carta, um diário etc. -, mas terá uma atitude responsiva diferente, pois terá a consciência de que, naquela contextualização, a carta ou o diário não estarão cumprindo suas funções sociais naturais, mas estarão a serviço do romance. Neste caso, ele saberá que o gênero está sendo utilizado por personagens da obra, ou seja, que o gênero funcionará muito bem, mas numa outra cena enunciativa - o leitor verá, então, uma carta num romance, sendo que esses gêneros não estão num mesmo patamar enunciativo -, logo, trata-se de uma constituição híbrida; o segundo é o fato de que há a necessidade de a carta/o diário precisarem aparecer na íntegra, simulando a sua real função social. Neste sentido, há obrigatoriedade da presença desses gêneros. Caso Os sofrimentos do jovem Werther e Drácula tivessem sido construídos em formas de narrativas tradicionais, naturalmente não haveria misturas genéricas.

A necessária presença de dois (ou mais) gêneros em um outro já diferencia este tipo de mescla da anterior, que se caracteriza por não ter essa obrigatoriedade para que o sentido seja construído. Na mescla por gêneros casualmente ocorrentes, a retirada do infográfico, por exemplo, no máximo diminuiria as informações da reportagem, mas esta não deixaria de existir. Já na mescla por gêneros intercalados, em não havendo cartas, diários etc. em sua composição original, é o romance que não existiria - ou existiria, mas formatado diferentemente. São preocupações da Literatura as implicações disso, como a análise da obra, a recepção pelo público, o seu significado para a sociedade etc.

$\mathrm{Na}$ verdade, é a este tipo de mescla genérica que Koch e Elias (2006) se referem, quando trazem em sua obra a figura 5 para explicar a intergenericidade. 
O anúncio, assim como o romance, tem uma constituição bastante maleável, tanto que seria redutor tentar expressar uma organização retórica. Ele também pode se constituir por mesclas, que é o que se observa na figura 5 .

Figura 5 - Mescla por gêneros intercalados:

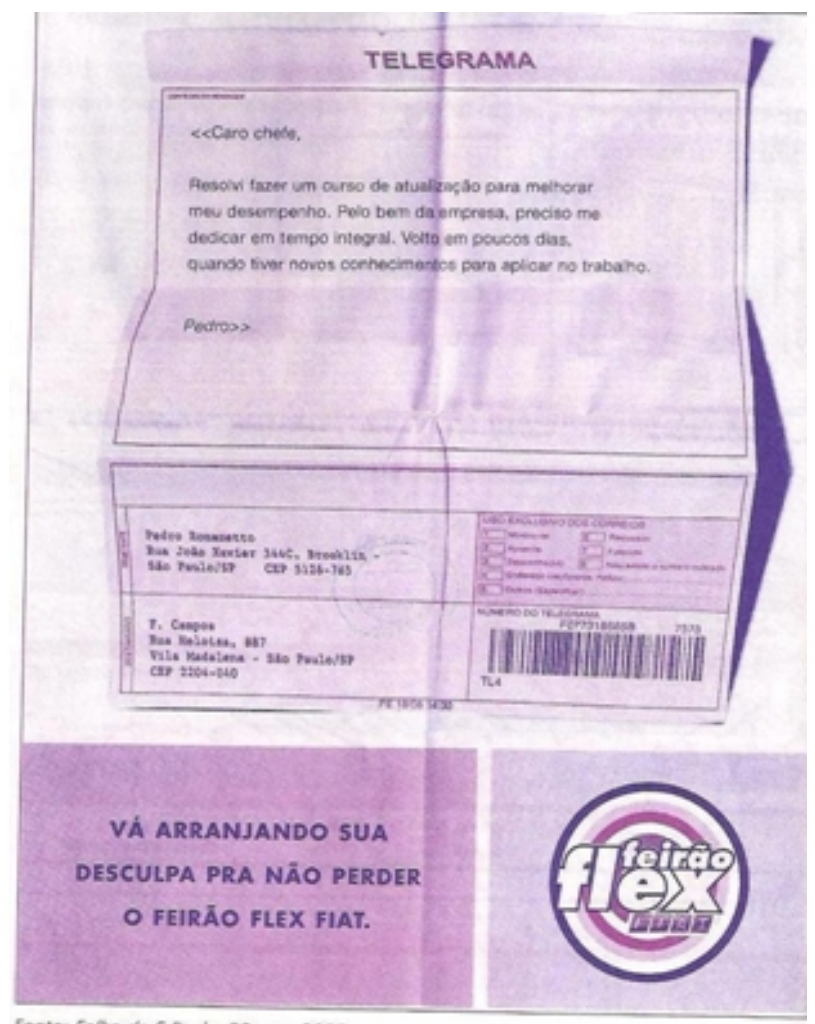

Fonte: Foha de S Paulo, 20 ago. 2005.

Fonte: Koch e Elias (2006, p. 116). 
Vemos neste exemplo um anúncio de feira de automóveis, construído com o uso de um telegrama de um funcionário (Pedro) a seu chefe. Aqui reside a distinção desta mescla em relação às outras: o leitor da Folha de S. Paulo não levaria em consideração a função social do telegrama, pois este está imerso no anúncio. Logo, não faz parte da enunciação do leitor, embora ele o reconheça como um outro gênero, utilizado em outras circunstâncias comunicativas. Se observarmos a enunciação dos interlocutores, o telegrama será considerado um gênero do cotidiano, ou seja, o enunciador do telegrama - Pedro - efetivamente comunicou ao seu superior, por meio do gênero telegrama, um afastamento por poucos dias. Entretanto, considerar a enunciação dos interlocutores nos obrigaria a acionar dispositivos de uma análise menos linguística do gênero textual e, talvez, mais próxima dos interesses de uma análise literária. $\mathrm{O}$ nosso interesse, portanto, não é a análise do que poderiam pensar os enunciadores do gênero transmutado, sujeitos fictícios, mas a recepção do coenunciador do gênero transmutante, o leitor do anúncio, neste caso, usuário do gênero, o qual saberá que se trata de uma imitação de toda uma função social exercida pelo gênero telegrama, neste caso, redimensionada para cumprir o propósito do gênero anúncio. Caso este telegrama não aparecesse da forma que está, o título do anúncio ("Vá arranjando sua desculpa para não perder o Feirão Flex Fiat”) também não seria o mesmo. Como enunciadores do gênero anúncio, os diretores de arte e os redatores teriam de encontrar uma outra forma de promover o "Feirão Fiat Flex".

Considerando as três formas de mesclar gêneros elencadas por nós, há diferenças entre a mescla por gêneros intercalados e a intergenericidade prototípica porque, nesta, características de dois gêneros (forma, função, suporte, estilo, propósito etc.) são amalgamadas, não sendo possível delimitar as fronteiras de cada um. Na saliência de uma dessas características, há a definição do gênero. Já quanto à mescla por gêneros casualmente ocorrentes, os padrões de gêneros - estrutura, conteúdo, estilo, propósito - são facilmente identificáveis, de forma que um não ocupa o espaço do outro, traço que se aproxima da mescla por gêneros intercalados, não fosse o fato de, nesta, última, a relação 
existente entre os gêneros ser de outra natureza: o telegrama faz parte do anúncio, mas não necessariamente complementa as informações dele originalmente, o telegrama tem outros propósitos, alheios à promoção de um produto, e eles foram redimensionados para outro objetivo -, como ocorre com o infográfico. Os propósitos comunicativos dos gêneros na mescla em análise são diferentes (o telegrama informa; o anúncio vende), ao passo que a relação entre a reportagem e o infográfico é mais simbiótica: um complementa o outro, e ambos voltam os seus propósitos para informar/explicar um fato. Além disso, se os gêneros forem vistos sob enunciações distintas (a do leitor e a dos enunciadores), também teremos interpretações variadas. Para o leitor, o telegrama, embora seja reconhecido, não cumpre o seu papel, pois não está sendo utilizado na função social para a qual foi preparado. É apenas parte (obrigatória) deste anúncio em específico.

\section{DAS CONSIDERAÇÕES (SEMI)FINAIS}

O que buscamos mostrar com essa análise é que o que a literatura especializada chama de intergenericidade deve ser repensado por dois motivos: em primeiro lugar, numa mescla de gêneros desta natureza, não entram em jogo apenas dois traços genéricos, a saber, a forma e o propósito, mas, muitas vezes, estilo, suporte, conteúdo etc.; em segundo lugar, o que tem se apresentado como intergenericidade na literatura teórica sobre o assunto não tem dado conta das variadas formas de mesclar gêneros na sociedade, algo comum no cotidiano dos usuários da língua. Por isto, sugerimos distinguir tipos de mesclas, embora sejamos conscientes de que a nomenclatura que utilizamos talvez não seja fiel ao fenômeno.

É importante que fique claro que esta categorização não esgota os tipos de mesclas genéricas. Em Lima-Neto (2009), por exemplo, foi encontrada uma outra mescla, denominada "Mescla por gêneros coocorrentes", mas foi definido com dados do meio digital, à ocasião, o universo da pesquisa, que muito difere do que acontece na mídia impressa. É provável, inclusive, que mesclas outras ainda apareçam na 
hipertextualidade digital, pois a web, no nosso entender, é o espaço das misturas por excelência: lá se cruzam domínios discursivos (a partir do momento em que se encontra qualquer coisa de qualquer área do conhecimento), de semioses (som, imagem e escrita coocorrem, exigindo mais cognitivamente dos usuários), de comunidades (é só verificar sites de relacionamento, como o Facebook, ou sites que propiciam listas de discussão, como o Yahoo!, onde milhões de pessoas das mais variadas procedências convivem e discutem os mais variados temas) e principalmente de culturas. É natural que isso se reflita nas práticas de linguagem. Mas isto é assunto para outros estudos.

\section{REFERÊNCIAS}

ARAÚJO, J. C. Os chats: uma constelação de gêneros na internet. 2006. 341 f. Tese (Doutorado em Linguística) - Programa de Pós-graduação em Linguística, Universidade Federal do Ceará, Fortaleza, 2006.

ASKHAVE, I.; SWALES, J. M. Genre identification and communicative purpose: a problem and a possible solution. Applied Linguistics, Oxford (UK), v. 22, n. 2, p. 195-212, 2001.

BAKHTIN, M. Problemas da poética de Dostoiévski. Rio de Janeiro: Ed. Forense-Universitária, [1929] 2005.

. Os gêneros do discurso. In: . Estética da criação verbal. São

Paulo: Martins Fontes, [1953] 2006.

BHATIA, V. K. Analysing genre: language use in professional settings. London: Longman, 1993.

CAVALCANTE, M. M. Intertextualidades: critérios classificatórios. In:

ENCONTRO LINGUÍSTICO E LITERÁRIO DO MESTRADO EM LETRAS \& I ENCONTRO REGIONAL DO ENMEL, 2., 2007, Teresina. Anais... Teresina: UFPI, 2007.

FIX, U. O cânone e a dissolução do cânone. A intertextualidade tipológica - um recurso estilístico "pós-moderno"? Revista de Estudos da Linguagem, Belo Horizonte, v. 14, n. 1., p. 261-281, jan./jun. 2006.

GEERTZ, C. Mistura de gêneros: a reconfiguração do pensamento social. In: O saber local. 3. ed. Editora Vozes: Petrópolis, 1983. 
HANKS, W. F. Texto e textualidade. In: BENTES, A. C.; REZENDE, R. C.; MACHADO, M. A. R. (Orgs.). Língua como prática social: das relações entre língua, cultura e sociedade a partir de Bourdieu e Bakhtin. São Paulo: Cortez, 2008, p. 118-168.

KOCH, I. V.; ELIAS, V. M. Ler e compreender os sentidos do texto. 2. ed. São Paulo: Contexto, 2006.

KOCH, I. V.; BENTES, A. C.; CAVALCANTE, M. M. Intertextualidade: diálogos possíveis. São Paulo: Cortez, 2007.

KRESS, G.; VAN LEEUWEN, T. Reading images: the grammar of visual design. 2 ed. London; New York: Longman, [1996] 2006.

LIMA-NETO, V. Mesclas de gêneros no Orkut: o caso do scrap. 2009. 213 f. Dissertação (Mestrado em Linguística) - Programa de pós-graduação em Linguística, Universidade Federal do Ceará, Fortaleza, 2009.

MARCUSCHI, L. A. Gêneros textuais: definição e funcionalidade. In: DIONÍSIO, A. P.; MACHADO, A. R.; BEZERRA, M. A. (Orgs.). Gêneros textuais e ensino. Rio de Janeiro: Lucerna, 2002, p. 19-36.

Produção textual, análise de gêneros e compreensão. Rio de Janeiro: Parábola Editorial, 2008.

PAGANO, A. S. Gêneros híbridos. In: MAGALHÃES, C. (Org.). Reflexões sobre a Análise Crítica do Discurso. Estudos Lingüísticos. v. 2. Belo Horizonte: POSLING-UFMG, 2001. p. 83-103.

SWALES, J. M. Genre analysis: English in academic and research settings. Cambridge: Cambridge University Press, 1990.

Re-thinking genre: another look at a discourse community effects. In:

Re-Thinking Genre Colloquium. Ottawa, Carleton University, 1992.

PAIVA, F. A. A leitura de gênero textual multimodal: a hipertextualidade do infográfico. In: CONGRESSO INTERNACIONAL DA ABRALIN. 6., 2009, João Pessoa. Anais... João Pessoa: UFPB, 2009. v. 1. p. 3666-3674.

STOKER, B. Drácula. São Paulo: Martin Claret, 2007.

ZAVAM, A. Por uma abordagem diacrônica dos gêneros do discurso à luz da concepção de tradição discursiva: um estudo com editoriais de jornal. 2009. 420 f. Tese (Doutorado em Linguística) - Programa de Pós-graduação em Linguística, Universidade Federal do Ceará, Fortaleza, 2009. 
Recebido em: 08/08/11. Aprovado em 21/04/12.

Title: Revisiting the concept of intergenericity

Authors: Vicente de Lima-Neto; Júlio César Araújo

Abstract: This paper aims to revisit the intergenericity, a concept that deals with genre mixture. Based on Bakbtin's reflections (2006 [1953]) on reelaboration and genre mixture, we seek arguments to support the thesis that the concept of intergenericity, as it has been proposed by Text Linguistics, does not account for all the different forms of text in which genres are mixed. We propose three different types of genre mixture: the prototype intergenericity mixture, characterized by the fusion of traces of, at least, two genres; the casually occurring genre mixture; that consists of genres that do not necessarily combine, but that coexists in a symbiotic relationship, considering a common communicative purpose; and the interspersed genre mixture, which involves genres that can belong to different enunciative scenes.

Keywords: Genres. Intergenericity. Genre mixture.

Titulo: Por una rediscusión del concepto de intergenericidad

Autores: Vicente de Lima-Neto; Júlio César Araújo

Resumen: Este ensayo tiene como objetivo rediscutir la intergenericidad, concepto que estudia las mezclas de géneros. Con base en las reflexiones de Bakbtin (2006 [1953]) sobre reelaboraciones y mezclas de géneros, buscamos argumentos que sostengan la tesis de que el concepto de intergenericidad, tal cual viene siendo propuesto por la Lingüistica de Texto, no contempla todas las diferentes formas de manifestación textual en que se mezclan géneros. Proponemos tres tipos de mezclas genéricas distintas: la mezcla por intergenericidad prototípica, caracterizada por la fusión de trazos de por lo menos dos géneros; la mezcla por géneros casualmente ocurrentes; constituida por géneros que no necesariamente se funden, mas que coexisten en una relación simbiótica, volcada para un propósito comunicativo común; y la mezcla por géneros intercalados, que envuelve géneros que pueden pertenecer a escenas enunciativas distintas.

Palabras-clave: Géneros. Intergenericidad. Mezcla de géneros.

NETO; ARAÚJO - Por uma rediscussão do conceito de intergenericidade 